\title{
МИГРАЦИОННЫЕ ПЛАНЫ ВЫПУСКНИКОВ МОЛДАВСКИХ ВУЗОВ *
}

\author{
ВАЛЕРИЙ МОШНЯГА, ВАЛЕНТИН ЦУРКАН
}

\begin{abstract}
Миграционные планы выпускников молдавских вузов ориентированы в первую очередь на выезд в другие страны, возвращение на прежнее место жительства и миграцию в «другой населенный пункт» страны. Потенциальная миграция выпускников мотивируется такими факторами, как «приемлемый уровень жизни», «возможность получения высоких доходов» и «культурная среда». Возвратные мигранты прежде всего рассчитывают на хорошую зарплату и возможность найти интересную работу, на помощь родственников.

Выталкиваюшие факторы, в первую очередь, носят экономический характер: предполагаемая заработная плата большинства выпускников не позволяет рассчитылвать на статус «семьи со средними доходами». Информаџия о потенциальных мигрантах среди студенческой молодежи важна, так как позволяет, во-первых, увидеть эффективность высшего образования с точки зрения обеспеченности Молдавии высокообразованными кадрами; во-вторых, определить те профессии, которые в наибольшей степени подвергаются «утечке мозгов»; в-третьих, такая информация необходима для обеспечения безопасности той части выпускников, которая в скором времени реализует свои миграционные планы как в стране, так и вне ее.
\end{abstract}

Результаты исследования могут быть использованы для принятия управленческих решений $в$ области молодежной, миграџионной и образовательной политики.

Ключевые слова: учебная миграция, внутренняя миграция, возвратная миграция, международная миграция, миграциинные намерения.

В статье представлены основные результаты исследования миграционных планов выпускников столичных и региональных вузов Молдавии, в том числе оценка объема и структуры потенциального миграционного потока и характеристика факторов, влияющих на формирование миграционных намерений выпускников. Эмпирической основой исследования послужили результаты опроса 917 студентов выпускных курсов, проведенного весной-осенью 2013 г. в девяти молдавских вузах, расположенных в столице - муниципии Кишиневе, а также в муниципиях Бельцы и Комрат. Методологически анализ основывается на подходах, используемых для исследования миграционных процессов Центром по изучению проблем народонаселения МГУ, Исследовательским центром Высшей школы экономики (О.С. Чудиновских и др.), в частности, для исследования факторов, определяющих миграционное поведение и выбор направлений потенциальной миграции.

ВАЛЕРИЙ ГЕОРГИЕВИЧ МОШНЯГА, МОЛДАВСКИЙ ГОСУДАРСТВЕННЫЙ УНИВЕРСИТЕТ. МОЛДАВИЯ. ВАЛЕНТИН ДМИТРИЕВИЧ ЦУРКАН, МОЛДАВСКИЙ ГОСУДАРСТВЕННЫЙ УНИВЕРСИТЕТ. МОЛДАВИЯ. E-mail: vals6412@yandex.ru

СТАТЬЯ ПОСТУПИЛА В РЕДАКЦИЮ В ЯНВАРЕ 2015 Г.

* СТАТЬЯ ОСНОВАНА НА РЕЗУЛЬТАТАХ ПРОЕКТА «ОЦЕНКА МИГРАЦИОННОГО ПОТЕНЦИАЛА СТУДЕНТОВ ВЫПУСКНЫХ КУРСОВ ВЫСШИХ УЧЕБНЫХ ЗАВЕДЕНИЙ РЕСПУБЛИКИ МОЛДОВА», ВЫПОЛНЕННОГО В РАМКАХ ПРОГРАММЫ ФУНДАМЕНТАЛЬНЫХ ИССЛЕДОВАНИЙ НИУ ВШЭ В 2013 Г. ГРУППОЙ СОЦИОЛОГОВ НИЛ «СОЦИОЛОГИЯ ПОЛИТИКИ» МОЛДАВСКОГО ГОСУДАРСТВЕННОГО УНИВЕРСИТЕТА. РУКОВОДИТЕЛИ ИССЛЕДОВАНИЯ В.Г. МОШНЯГА, В.Д. ЦУРКАН. 


\section{ОСНОВНЫЕ ХАРАКТЕРИСТИКИ РЕСПОНДЕНТОВ}

Информация о распределении респондентов по вузам, форме обучения (бюджетная/контрактная) и месту проживания до поступления (местные/иногородние) представлена в таблице 1 .

\section{Таблица 1. Распределение респондентов по вузам, форме обучения и месту проживания}

\begin{tabular}{|c|c|c|c|c|}
\hline \multirow[b]{2}{*}{ Вуз } & \multicolumn{2}{|c|}{ Опрошено } & \multirow{2}{*}{ 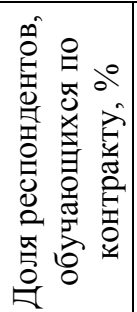 } & \multirow{2}{*}{ 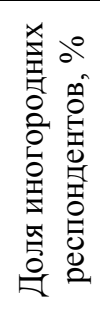 } \\
\hline & 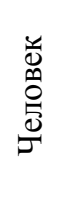 & 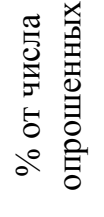 & & \\
\hline Академия публичного управления & 19 & 2,1 & 21,1 & 21,1 \\
\hline Академия экономических знаний Молдавии & 139 & 15,2 & 67,6 & 56,8 \\
\hline $\begin{array}{l}\text { Бельцкий государственный педагогический университет } \\
\text { им. Алеку Руссо }\end{array}$ & 57 & 6,2 & 47,4 & 73,7 \\
\hline $\begin{array}{l}\text { Государственный университет медицины и фармацевтики им. } \\
\text { Н. Тестемицану }\end{array}$ & 147 & 16,0 & 22,4 & 70,1 \\
\hline Молдавский государственный университет & 348 & 37,9 & 57,3 & 57,8 \\
\hline Комратский государственный университет & 32 & 3,5 & 65,6 & 71,9 \\
\hline Международный институт менеджмента IMI-NOVA & 31 & 3,4 & 100,0 & 19,4 \\
\hline Технический университет Молдавии & 136 & 14,8 & 37,5 & 60,3 \\
\hline Университет Высшая антропологическая школа & 8 & 0,9 & 62,5 & 12,5 \\
\hline Итого & 917 & 100,0 & 50,8 & 59,0 \\
\hline
\end{tabular}

Большинство респондентов $(93,6 \%)$ заканчивают бакалавриат, $6,4 \%$ - магистратуру.

Такое распределение отражает существующую двухуровневую систему высшего профессионального образования в Молдавии ${ }^{1}$.

Немногим больше половины респондентов $(50,8 \%)$ учатся за счет государственного бюджета. Наиболее распространено контрактное обучение в вузах и на факультетах, готовящих специалистов по популярным направлениям, к которым относятся в первую очередь «право» $(89,7 \%)$, «стоматология» $(70,4 \%)$, «журналистика и науки коммуникации» $(81,4 \%)$, «экономика и управление» $(67,6 \%)$. Распределение респондентов на две базовые для нашего исследования группы - местных (которые проживали до поступления и продолжают жить в том же городе, где учатся) и иногородних (приехавшие на учебу из других мест) - показало, что доля местных среди выпускников, участвующих в исследовании, составила 41,0\%, иногородних - 59,0\%. Вузы отличаются значительной дифференциацией по этому показателю.

\footnotetext{
${ }^{1}$ Высшее университетское образование в Молдавии длится от 3 до 6 лет в зависимости от направления подготовки. По завершении присуждаются дипломы лиценциата (Diploma de Licenta) или профессиональные дипломы (Doctor-Medic или Diploma de inginer). Вторая ступень высшего университетского образования ведет к получению диплома доктора (Diploma de Doctor) после 3 или 4 лет дополнительного обучения по завершении первой ступени высшего образования. Высшей научной квалификацией в настоящее время в Молдавии является ученая степень хабилитированного доктора (Doctor habilitat), присуждаемая во всех основных научных областях. Претенденты на получение этой квалификации должны иметь диплом доктора по соответствующему научному направлению.
} 
Лидерами по доле иногородних студентов (внутренние учебные мигранты) оказались три вуза: два региональных - Бельцский государственный педагогический университет им. Алеку Руссо - 73,7\% (42 из 57 респондентов), Комратский государственный университет - 71,9\% (23 из 32 респондентов) и один столичный Государственный университет медицины и фармацевтики им. Н. Тестемицану - 70,1\% (103 из 147 респондентов). Среди первых трех вузов с наибольшей долей местных (немигрантов/стайеров) можно выделить Университет Высшая антропологическая школа (87,5\%, 7 из 8 респондентов), Международный институт менеджмента IMI-NOVA (80,6\%, 25 из 31 респондентов) и Академию публичного управления (78,9\%, 15 из 19 респондентов).

Среди опрошенных 68,7\% составили девушки и 31,3\% - юноши. В целом, как и в генеральной совокупности, доля девушек (56,3\%) преобладает над юношами $(41,7 \%)$. В выборке количество девушек среди респондентов оказалось завышенным на 12,4\%, а юношей заниженным на 10,3\%.

Средний возраст респондентов составлял 23,4 года. Молодежь в возрасте 21-23 года составляет 93,9\%.

Возрастная структура студентов старших курсов молдавских вузов («молодые взрослые» - young adults) состоит из начальной (20-22 года, 66,6\%), средней (23-25 лет, $28,5 \%$ ) и старшей (26-28 лет, 2,8\%) групп (таблица 2).

Таблица 2. Возрастные группы студентов старших курсов молдавских вузов, категории «молодых взрослых»

\begin{tabular}{l|c|c|c}
\hline Год рождения, категория & Возраст, лет & Частота & \multicolumn{1}{c}{$\%$} \\
\hline 1993-1991 (начальная группа) & $20-22$ & 611 & 66,6 \\
1990-1988 (средняя группа) & $23-25$ & 261 & 28,5 \\
1987-1985 (старшая группа) & $26-28$ & 26 & 2,8 \\
1986-1976 & $29-37$ & 33 & 3,1 \\
Итого & \multicolumn{4}{|c}{917} & 100,0 \\
\hline aнные по возрастной группе 20-22 годa - [Houle 2014]; 29-37 лет - [Harper 2013].
\end{tabular}

Большинство опрошенных выпускников никогда не состояли в браке $(83,9 \%) ; 11,7 \%$ ответили, что состоят в зарегистрированном браке, 3,8\% - в незарегистрированном браке. Дети имеются у $5,1 \%$ респондентов.

\section{ВЫБОР МЕСТА УЧЕБЫ И МИГРАЦИОННОЕ ПОВЕДЕНИЕ ПРИ ПОСТУПЛЕНИИ В ВУЗ}

Выбор вуза, по оценкам респондентов, определяется, главным образом, тремя факторами: хороший уровень образования отметили 47,9\% опрошенных, престиж вуза - 45,3\% и престижность факультета/направления подготовки - 33,4\% (таблица 3). 
Таблица 3. Ключевые факторы, определяющие выбор вуза

\begin{tabular}{|l|l|r|r|}
\hline & $\begin{array}{l}\text { Какие ключевые факторы повлияли на Ваш выбор вуза? (укажите не } \\
\text { более трех вариантов) }\end{array}$ & $\mathrm{N}$ & $\%$ \\
\hline 1 & Возможность учиться бесплатно & 267 & 29,1 \\
\hline 2 & Престиж вуза & 415 & 45,3 \\
\hline 3 & Престижный факультет, направление & 306 & 33,4 \\
\hline 4 & Вуз обеспечивает хороший уровень образования & 439 & 47,9 \\
\hline 5 & Отсрочка от армии & 11 & 1,2 \\
\hline 6 & Привлекала страна (для прибывших из других стран) & 8 & 0,9 \\
\hline 7 & Привлекал город, где находится вуз & 45 & 4,9 \\
\hline 8 & Местонахождение вуза в городе & 55 & 6,0 \\
\hline 9 & Настояли родители & 52 & 5,6 \\
\hline 10 & Друзья, которые поступали или учились в данном вузе & 95 & 10,4 \\
\hline 11 & Хотелось жить отдельно от родителей & 13 & 1,4 \\
\hline 12 & Не помню & 24 & 2,6 \\
\hline 13 & Другое & 55 & 6,0 \\
\hline
\end{tabular}

\section{ГЕНЕРАЛЬНАЯ СОВОКУПНОСТЬ}

Генеральная совокупность студентов выпускных курсов молдавских вузов в 20122013 учебном году составила 26730 человек (таблица 4). Из них в Кишиневе училось 89,7\% (23 969 человек), в Бельцах - 6,9\% (1 834), в Комрате - 1,6\% (419), в Кагуле - 1,6\% (430) и в Тараклии - 0,3\% (430).

\section{Таблица 4. Генеральная совокупность студентов выпускных курсов молдавских} вузов в 2012-2013 учебном году

\begin{tabular}{l|r|r}
\hline Вуз & $\mathrm{N}$ & \multicolumn{1}{c}{$\%$} \\
\hline Муниципий Кишинев (28 вузов) & 23969 & 89,7 \\
Муниципий Бельцы (3 вуза) & 1834 & 6,9 \\
Муниципий Комрат (1 вуз) & 419 & 1,6 \\
Город Кагул (1 вуз) & 430 & 1,6 \\
Город Тараклия (1 вуз) & 69 & 0,3 \\
Итого (34 вуза) & 26730 & 100,0 \\
\hline
\end{tabular}

Источник: [Educatia 2013].

\section{ВЫБОРОЧНАЯ СОВОКУПНОСТЬ}

Выборочная совокупность исследования (таблица 5) студентов выпускных курсов представлена следующим образом: Кишинев - 8 вузов (90,3\%), Бельцы - 1 вуз (6,2\%), Комрат - 1 вуз (3,5\%). Сравнение данных генеральной совокупности (таблица 4) и выборочной совокупности (таблица 5) показывает высокий уровень репрезентативности выборки и результатов последующего анализа.

Таблица 5. Распределение выборочной совокупности в зависимости от города, где находится вуз

\begin{tabular}{l|r|r}
\hline Вуз, в котором учатся сейчас: & $\mathrm{N}$ & $\%$ \\
\hline Кишинев (8 вузов) & 828 & 90,3 \\
Бельцы (1 вуз) & 57 & 6,2 \\
Комрат (1 вуз) & 32 & 3,5 \\
Итого & 917 & 100,0 \\
\hline
\end{tabular}


Нам представляется достаточно важным наличие миграционного опыта студентов выпускных курсов, который они приобрели: а) в период поступления в вуз; в) в процессе обучения в вузе; с) на этапе завершения обучения в вузе и выбора дальнейшего жизненного пути. В зависимости от миграционного опыта мы выделяем три миграционные позиции: стартовая, в период обучения в вузе и заключительная.

\section{СТАРТОВАЯ МИГРАЦИОННАЯ ПОЗИЦИЯ ПЕРЕД ПОСТУПЛЕНИЕМ В ВУЗ}

Студенты выпускных курсов в зависимости от стартовой позиции перед поступлением в вуз и последующего обучения на выпускных курсах могут быть разделены на две группы (таблица 6). К первой группе (383 человека, 41,8\%) относятся студенты выпускных курсов, которые проживали непосредственно перед поступлением в муниципиях (Кишинев, Бельцы, Комрат) и в которых они продолжали учиться во время опроса. Другая группа студентов (534 человека, 58,2\%) непосредственно перед поступлением проживала в других городах/населенных пунктах. Таким образом, 41,8\% студентов находились в стайерской (немиграционной) ситуации, в то время как 58,2\% изначально объективными и субъективными факторами были поставлены в ситуацию внутренних учебных мигрантов.

Из 383 студентов выпускных курсов девяти вузов Молдавии проживали перед поступлением в вуз в Кишиневе 358 (93,5\%) студентов, в Бельцах 16 (4,2\%) и в Комрате 9 $(2,3 \%)$.

В то же время в столичных вузах обучаются 40 студентов из других городов (Бельцы - 22, Комрат - 8, Тирасполь - 10) по специальностям, не имеющим аналогов в вузах места проживания (таблица 7).

Таблица 6. Распределение студентов выпускных курсов молдавских вузов в зависимости от места проживания непосредственно перед поступлением (или переводом) в вуз, в котором учились во время опроса

\begin{tabular}{|c|c|c|}
\hline & $\mathrm{N}$ & $\%$ \\
\hline \multicolumn{3}{|l|}{ 1. Проживали в том же городе/населенном пункте, где находится вуз } \\
\hline Кишинев & 358 & 93,5 \\
\hline Бельцы & 16 & 4,2 \\
\hline Комрат & 9 & 2,3 \\
\hline Итого & 383 & 100 \\
\hline \multicolumn{3}{|l|}{ 2. Проживали в другом городе/населенном пункте } \\
\hline Бельцы & 22 & 4,1 \\
\hline Комрат & 8 & 1,5 \\
\hline Тирасполь & 10 & 1,9 \\
\hline Другие города & 226 & 40,0 \\
\hline Сельская местность & 269 & 50,4 \\
\hline Другие страны & 9 & 1,7 \\
\hline Итого & 534 & 100 \\
\hline Проживали в том же городе/населенном пункте, где находится вуз & 383 & 41,8 \\
\hline Проживали другом городе / населенном пункте & 534 & 58,2 \\
\hline Всего & 917 & 100 \\
\hline
\end{tabular}


Таблица 7. Студенты выпускных курсов, проживавшие до поступления в вуз в Бельцах, Комрате и Тирасполе, получающие образование в столичных вузах

\begin{tabular}{|c|c|c|c|c|}
\hline \multirow[t]{2}{*}{ Название вуза } & \multirow[t]{2}{*}{ Специальность } & \multicolumn{3}{|c|}{$\begin{array}{l}\text { Проживали непосредственно перед } \\
\text { поступлением в: }\end{array}$} \\
\hline & & Бельцах & Комрате & Тирасполе \\
\hline Академия экономических знаний & бухгалтерский учет & 1 & & \\
\hline \multirow[t]{3}{*}{ Молдавии } & маркетинг & 2 & & \\
\hline & социальный менеджмент & 1 & & \\
\hline & банки и финансы & & 3 & \\
\hline \multirow{7}{*}{$\begin{array}{l}\text { Молдавский государственный } \\
\text { университет }\end{array}$} & журналистика & 1 & 1 & \\
\hline & $\begin{array}{l}\text { производство косметических и } \\
\text { медицинских продуктов }\end{array}$ & 1 & 1 & \\
\hline & химия & 1 & 1 & \\
\hline & информационные технологии & & & 1 \\
\hline & социальная работа & & & 1 \\
\hline & социология & & & 1 \\
\hline & физика & & & 1 \\
\hline Технический университет & инженерия и менеджмент в & & & \\
\hline \multirow[t]{6}{*}{ Молдовы } & $\begin{array}{l}\text { электронике и } \\
\text { телекоммуникациях }\end{array}$ & 3 & & \\
\hline & $\begin{array}{l}\text { инженерия и менеджмент в } \\
\text { энергетике }\end{array}$ & 1 & & \\
\hline & компьютеры & 2 & 1 & 2 \\
\hline & микроэлектроника & 1 & & \\
\hline & телерадиокоммуникации & 1 & & \\
\hline & информационные технологии & & & 2 \\
\hline Государственный университет & медицина & 6 & & \\
\hline медицины и фармацевтики им. & фармакология & 1 & & \\
\hline Н.Тестемицану & стоматология & & & 2 \\
\hline Итого & & 22 & 8 & 10 \\
\hline
\end{tabular}

Мотивация на специальности, не имеющие аналогов в вузах таких региональных центров, как Бельцы и Комрат, играет важную роль притягательного фактора в миграционном перемещении в столичные вузы Молдавии. И наоборот, среди студентов выпускных курсов вузов Бельц и Комрата нет тех, кто проживал до поступления в Кишиневе. Т.е. притягательных миграционных факторов для абитуриентов, проживающих в Кишиневе, в вузах Бельц и Комрата наше исследование не зафиксировало.

Таким образом, можно сделать вывод, что разделение студентов выпускных курсов в Молдавии при поступлении в вузы определялось сложившимся исторически распределением вузов и профессий (специальностей) в столице (Кишинев), в среднем (Бельцы) и небольшом (Комрат) городе.

\section{МИГРАЦИОННЫЕ ОРИЕНТАЦИИ СТУДЕНТОВ В ПРОЦЕССЕ ОБУЧЕНИЯ В ВУЗЕ}

Формирование отношения студентов к миграции в процессе обучения в вузе - это естественный процесс поиска своего места в обществе. Решающую роль на этом этапе играет уже не опыт, полученный ранее в месте жительства до поступления в вуз, а новый опыт студенческой жизни, включающий и оценку качества обучения в вузе. Миграционная мобильность в этот период может реализоваться в виде учебной мобильности, перехода из одного вуза в другой, она также существует реально в виде обучения студентов в течение 
одного или нескольких семестров в зарубежном вузе и непосредственного участия студентов в учебном процессе этого вуза. При этом и формируются миграционные ориентации студентов, которые либо реализуются лишь частично, либо не реализуются и остаются на латентном уровне. Ниже рассмотрим латентные миграционные ориентации студентов.

Формирование миграционных ориентаций студентов выпускных курсов определялось с помощью вопроса: «повторил бы или не повторил бы выбор вуза или специальности».

\section{Таблица 8. Изменение или появление новых миграционных ориентаций в ситуации неудовлетворенности качеством обучения в вузе или избранной специальностью}

\begin{tabular}{l|rr}
\hline Если бы вам представилась возможность заново выбирать место обучения, то Вы бы & Частота & $\%$ \\
выбрали & 433 & 47,2 \\
\hline Тот же вуз и тот же факультет & 162 & 17,7 \\
Тот же вуз, но другой факультет & 26 & 2,8 \\
Тот же факультет, но в другом вузе моей страны & 96 & 10,5 \\
Тот же факультет (направление подготовки), но в вузе другой страны & 67 & 7,3 \\
Другой вуз, другой факультет (направление подготовки) моей страны & 54 & 5,9 \\
Другой вуз, другой факультет (направление подготовки) другой страны & 79 & 8,6 \\
Затрудняюсь ответить & 917 & 100,0 \\
Итого & 917 \\
\hline
\end{tabular}

Как видно из таблицы 8, 47,2\% респондентов выбрали бы тот же вуз и тот же факультет и 17,7\% - тот же вуз, но другой факультет. Большая часть респондентов $(64,9 \%)$ в процессе обучения не проявляют склонности к учебной миграции. Другая группа студентов демонстрирует два типа миграционных ориентаций: внешний (на обучение в другой стране) - 16,4\% и внутренний (другой вуз на территории Молдавии) - 10,1\%.

Качество профессионального образования - важнейшая переменная, определяющая будущую успешность или неуспешность профессиональной деятельности и, следовательно, уровень доходов. Практика подсказывает, что основной причиной миграционных ориентаций в процессе обучения выступает фактор неудовлетворенности качеством образования в вузе обучения.

Связь формирования миграционных ориентаций у студентов выпускных курсов в процессе обучения и удовлетворенности/неудовлетворенности качеством образования, получаемого в вузе, представлена в таблице 9.

Как видим, ориентация на миграционное перемещение характеризует обе группы как удовлетворенных, так и неудовлетворенных качеством получаемого образования. В то же время следует отметить, что среди респондентов, в той или иной степени удовлетворенных качеством образования, получаемого в вузе, миграционные ориентации развиты в значительно меньшей степени, чем среди неудовлетворенных качеством обучения. Большую или меньшую распространенность миграционных ориентаций можно оценить с помощью специального показателя - Индекса миграционной ориентации (ИМО)ㄹ․

2 Индекс миграционной ориентации (ИМО) высчитывается по формуле: ИМО = К1-К2/К, где К1 количество планирующих заново выбрать место обучения, К2 - количество не желающих заново выбрать место обучения и К - общее количество ответов. Численное значение такого индекса колеблется от +1 до - 
Этот показатель отрицательный среди удовлетворенных полностью качеством обучения (0,66; $14 \%)$, и положительный среди неудовлетворенных качеством обучения $(+0,31 ; 60 \%)$. В группе «не вполне удовлетворенных» качеством образования ИМО так же имеет отрицательное значение $(-0,09)$.

\section{Таблица 9. Взаимосвязь миграционных ориентаций и удовлетворенности качеством} образования, получаемого в вузе, \%

\begin{tabular}{|c|c|c|c|c|c|c|c|c|c|}
\hline \multirow[b]{2}{*}{$\begin{array}{c}\text { Удовлетворены ли Вы } \\
\text { качеством образования, } \\
\text { получаемого в вузе? }\end{array}$} & \multirow[b]{2}{*}{ 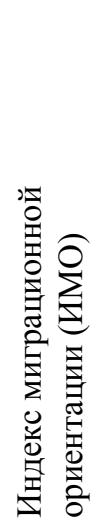 } & \multicolumn{8}{|c|}{$\begin{array}{c}\text { Если бы вам представилась возможность заново выбирать место } \\
\text { обучения, то Вы бы выбрали: }\end{array}$} \\
\hline & & 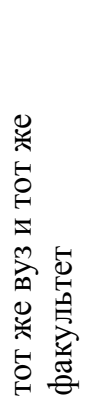 & 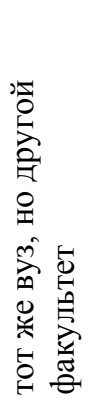 & 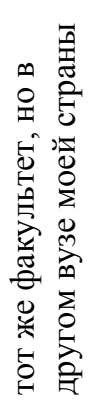 & 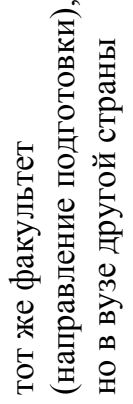 & 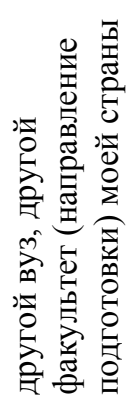 & 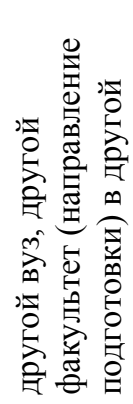 & 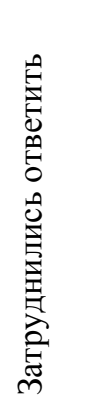 & Итого \\
\hline $\begin{array}{l}\text { Удовлетворен } \\
\text { полностью }\end{array}$ & $-0,66$ & 65,4 & 15,6 & 1,5 & 6,3 & 3,0 & 3,2 & 5,0 & 100,0 \\
\hline $\begin{array}{l}\text { Удовлетворен не } \\
\text { вполне }\end{array}$ & $-0,09$ & 27,8 & 21,4 & 4,9 & 15,3 & 12,5 & 7,3 & 10,7 & 100,0 \\
\hline Не удовлетворен & $+0,31$ & 14,3 & 14,3 & 8,6 & 11,4 & 17,1 & 22,9 & 11,4 & 100,0 \\
\hline Затрудняюсь ответить & $-0,27$ & 37,8 & 16,7 & 0 & 13,3 & 6,7 & 7,8 & 17,8 & 100,0 \\
\hline Итого & $-0,39$ & 47,3 & 17,7 & 2,8 & 10,4 & 7,3 & 5,9 & 8,5 & 100,0 \\
\hline
\end{tabular}

Рассмотрим, как влияет оценка качества обучения на формирование ориентации на внешнюю миграцию. Интерес к внешней миграции оправдан: внешняя миграция студентов в Молдавии часто является ступенью к эмиграции и, как следствие, одним из каналов потери для страны людей с высшим образованием. Данные таблицы 9 показывают, что неудовлетворенность качеством обучения в большей степени связана с ориентацией выпускников на внешнюю учебную миграцию: $33,3 \%(11,4 \%+22,9 \%)$. Среди удовлетворенных учебой на внешнюю учебную миграцию ориентированы только 9,5\% $(6,3 \%+3,2 \%)$ респондентов.

Приведенные данные показывают, что процесс формирования миграционных ориентаций студентов продолжается и в процессе обучения в вузе.

\section{ОБРАЗОВАТЕЛЬНАЯ МИГРАЦИЯ КАК РОЛЕВОЕ ПРОДВИЖЕНИЕ И ИНВЕСТИЦИИ В ЧЕЛОВЕЧЕСКИЙ КАПИТАЛ}

Как показано выше, поступление в вуз выпускников школ сельских и небольших городских поселений в Молдавии сопровождается миграционными перемещениями в основном в столицу и в меньшей степени в средний город. Несмотря на различие в исходных

1. Сдвиг численных значений к +1 или -1 означает общее направление соответственно к положительной реакции или к отрицательной ориентации на миграционное перемещение [Татарова 1999]. 
исследовательских парадигмах, и социологи, и экономисты сходятся во мнении: миграционное перемещение и высшее образование тесно переплетены. «Миграция и образовательные решения действительно переплетаются во многих измерениях» [Dustmann, Glitz 2011].

\section{Миграция и высшее образование как ролевое продвижение}

В рамках социологической парадигмы переход «от школы к стабильным (относительно) профессиональным статусам» [Чередниченко 2013] представляет собой средство для реализации индивидуальных ролевых экспектаций, сопутствующих данному возрастному этапу жизненного пути индивида. На возрастном этапе жизненного пути (life course) молодые взрослые используют миграцию и образование «не только для выполнения различных ролей, но также и для ... возможностей продвигаться в те из других, зачастую более престижных ролей, для выполнения которых они наилучшим образом приспособлены благодаря своим “природным» талантам”» [Барбер 1972: 239].

С точки зрения экономической парадигмы, абитуриента можно рассматривать как экономического агента, который, так же, как и трудовой мигрант, принимает индивидуальное миграционное решение о переезде в большой город для поступления в вуз с целью инвестиций в человеческий капитал. В ситуации выбора нового этапа жизненного пути абитуриент (а затем и выпускник вуза) выбирает миграционные перемещения как средство для получения высшего образования на основании сравнения ожидаемого дохода после окончания вуза в своем постоянном месте жительства. Если полученные знания и навыки позволят в будущем получить ожидаемый доход, то факт миграции и поступления в вуз будет иметь место. В ситуации выпускных курсов, если ожидаемый доход в месте постоянного проживания будет соответствовать уровню инвестиций в человеческий капитал ${ }^{3}$, то вероятно и возвращение в место постоянного проживания. Если же доход в месте постоянного проживания не будет соответствовать ожидаемому, то выпускник сменит место постоянного проживания и останется либо в городе, где он получает образование, либо в других странах и городах, которые обеспечат ему ожидаемый доход от инвестиций в человеческий капитал (высшее образование) [Варшавская, Чудиновских 2014].

Какими бы ни были факторы, обусловившие поступление в вуз, выпускник высшего учебного заведения ориентируется в последующем миграционном передвижении на достижения как социального (ролевого), так и экономического (инвестиционного) плана. Индивид стремится не просто получить престижные знания, но с их помощью или достичь престижной социальной роли (престижной профессии), или инвестировать их в «человеческий капитал», который позволит ему получить достойный капитал финансовый.

Финансовая стоимость престижной профессии и миграционные установки студентов выпускных курсов вузов Молдавии

Данные исследования показывают, что высшее образование как инвестиция в человеческий

\footnotetext{
${ }^{3}$ Как отмечает И. Молодикова [2006]: «Хорошее образование - это главный капитал молодого специалиста,
} вступающего на рынок труда». 
капитал непосредственно влияет на миграционное поведение студентов выпускных курсов вузов Молдавии. Среди мотивационных факторов, повлиявших на выбор вуза, престиж вуза и факультета занимает ведущее место: их совокупная оценка составляет 78,6\%. В современной Молдавии, как и в России, в отличие от недалекого совместного советского прошлого, сложилось отношение к профессии по принципу «профессия тем престижнее, чем она прибыльнее» [Малахова 2007].

В сложившейся ситуации можно предположить, что выпускники - «внутренние мигранты» станут «возвратными мигрантами», если их оценка престижа профессии совпадет с финансовой оценкой достигнутого человеческого капитала (профессиональных знаний). Если же реальная оценка достигнутого человеческого капитала окажется, с их точки зрения, недостаточной, то это приведет к формированию новых миграционных установок и к невозвращению.

Студенты - «внутренние мигранты» считают, что они могут рассчитывать после окончания вуза, если вернутся в город, из которого приехали на учебу в данный вуз, на среднемесячную зарплату от 2521,1 до 5081,5 леев ${ }^{4}$. Однако, чтобы нормально жить в городе, из которого они приехали на учебу, необходимо зарабатывать (по мнению студентов) в среднем 5802,4 леев (в большом городе (Бельцы) - 6017,6 леев, в малом городе - 6324,4 леев и в селе - 5362,6 леев). Таким образом, налицо (по мнению студентов) существенная недооценка накопленного человеческого капитала со стороны общества (государства). Вполне логично, что в этой ситуации миграционные установки получают дальнейшее развитие: остаться в городе, где они получили образование $(36,6 \%)$, или поискать «счастья» в другом населенном пункте своей страны $(4,4 \%)$ или в другой стране (21,3\%). Установки на «возвратную миграцию» демонстрируют 17,7\%, не определили своего отношения к миграционным планам 20,0\%.

Естественно, что получение престижного высшего образования ориентирует выпускника и на престижный уровень потребления. Однако, по мнению выпускников, их реальный уровень потребления весьма далек от ожидаемого.

Шкала уровней потребления в представлениях выпускников выглядит следующим образом: уровень потребления «богатой» семьи - 12867,7 леев дохода на одного человека, «среднего достатка» - 6361,5 леев и «бедной» - 2257,4 леев. Сравнивая ожидаемую выпускником заработную плату «от 2521,1 до 5081,5 леев», на которую, по мнению студентов, они могут рассчитывать, если вернутся в свой родной город, с ожидаемой, мы видим, что прогноз доходов его «будущей семьи» находится между доходами семей «бедных» и «со средним достатком». Едва ли такое будущее будет стимулировать студентов-мигрантов из небольших городов и сел Молдавии к добровольному возвращению в родные места. Если такое возвращение и состоится, то скорее всего будет реализовано в вынужденной ситуации.

Возможен другой путь решения проблемы удовлетворительной заработной платы после окончания вуза: остаться в городе, в котором студент учится. Однако само по себе

\footnotetext{
${ }^{4}$ Курс Национального банка Республики Молдова в 2013 г.:12 леев $=1 \$$. 
такое решение проблемы удовлетворительной заработной платы не решает. Чтобы нормально жить в городе обучения, необходимо зарабатывать, в среднем, (по оценкам студентов) 9275,9 леев в месяц. Сумма существенно большая, чем та, которую они предполагают заработать: от 2866,1 до 4778,0 леев в месяц. В такой ситуации для решения проблемы удовлетворительной заработной платы наиболее приемлемым решением является миграция в другую страну. В их «стране обетованной» предполагаемый заработок в месяц в среднем может составлять (по оценкам студентов) 20077,4 леев или 1673,1\$. Очевидно, данная месячная заработная плата в стране миграции и есть ответ на вопрос: «Сколько стоит внешняя миграция в представлении студентов выпускных курсов 2013/2014 учебного года»?

Таким образом, получение высшего образования сопровождается формированием у студентов-выпускников высокого уровня самооценки, т.е. оценки приобретенного ими человеческого капитала, не совпадающей с его реальной оценкой обществом и государством. Существование такого разрыва будет постоянным фактором миграционных установок, способствующих реальной трудовой миграции выпускников высших учебных заведений из Молдавии.

\section{СТУДЕНТ: МИГРАЦИОННОЕ ПОВЕДЕНИЕ И МИГРАЦИОННЫЕ ОРИЕНТАЦИИ}

В студенческой жизни миграция существует в двух видах: миграционное поведение как реализованное социальное действие и миграционные ориентации как нереализованное социальное действие. Решающую роль на этапе обучения оказывает уже не место жительства перед поступлением в вуз, а потребности студента: учебные, связанные с профессиональной подготовкой, и витальные, связанные с повседневной жизнью.

\section{Миграционное поведение}

Миграционное поведение исследовалось как посещения (кратковременные визиты) и как долговременное, т.е. проживание в зарубежных странах в течение более полугода.

Кратковременные визиты. В течение трех лет из общего количества респондентов посещали зарубежные страны 80,6\% (739), не посещали 19,1\% (175), т.е. каждый пятый.

Среди общего числа целевых стран миграции большая часть посетила страны СНГ (413; 56,0\%), ЕС (261; 35,4\%) и другие страны $(64 ; 8,7 \%)$.

Из стран СНГ на первом месте находится Украина (308; 74,6\%), на - втором Россия $(102 ; 24,7 \%)$, третье и четвертое места занимают Белоруссия $(2 ; 0,5 \%)$ и Грузия $(1 ; 0,2 \%)$.

Из стран ЕС на первом месте по посещаемости находится Румыния (141; 54,0\%), на втором - Болгария $(34 ; 13,0 \%)$, третье и четвертое места занимают Италия $(32 ; 12,3 \%)$ и Франция (13; 5,0\%).

Среди других стран первое место занимают США (42; 65,6\%), второе - Турция (34; $25,0 \%)$. 
Основные цели: туризм/отдых $(617 ; 83,5 \%)$, поездки в гости к родственникам/друзьям (228; 30,9\%), работа $(115 ; 15,6 \%)$.

Долговременные посещения (более полугода). Из общего числа стран миграции большая часть студентов посетила страны СНГ (30; 45,5\%), ЕС $(27 ; 40,9 \%)$, другие страны $(9 ; 13,6 \%)$.

Из стран СНГ на первом месте находится Россия $(21 ; 70,0 \%)$, на втором - Украина $(6 ; 20,0 \%)$, третье и четвертое места занимают Белоруссия $(2 ; 6,7 \%)$ и Киргизия $(1 ; 3,3 \%)$.

Из стран ЕС на первом месте по посещаемости находится Румыния (13; 48,1\%), на втором - Франция $(7 ; 25,9 \%)$, третье и четвертое места занимают Италия $(3 ; 11,1 \%)$ и Германия $(2 ; 7,4 \%)$. $22,2 \%)$.

Среди других стран первое место занимают США (6; 66,7\%), второе - Турция (2;

Основные цели: работа (29; 31,9\%), учеба (19; 20,9\%), туризм/отдых $(11 ; 12,1 \%)$.

Страны учебной мобильности студентов распределяются следующим образом: Румыния - 8, Россия - 3, Франция - 3, Италия - 2, Литва, Португалия, Украина - по 1.

Страны трудовой мобильности студентов распределяются следующим образом: Россия -13, Франция - 6, Румыния - 4, Италия, Германия, США, Украина - по 2, Белоруссия и Турция - по 1.

В целом можно отметить следующее.

Кратковременные посещения других стран в основном направлены на отдых, общение с близкими людьми и работу. На срок более полугода студенты едут в зарубежные страны на работу, учебу и отдых.

Наибольшее число посещений приходится на страны СНГ, на втором месте - ЕС. Чаще всего на короткий период студенты едут на Украину, на срок более полугода - в Россию.

Поездки в Россию привлекают студентов в большей мере с точки зрения трудовой, чем учебной мобильности: соответственно 13 и 3.

\section{Миграционные ориентации}

Работающий студент, с одной стороны, приобретает необходимый общий трудовой опыт, а с другой, - особенно необходимый выпускнику для последующего устройства на работу профессиональный стаж. Следовательно, студенты, в процессе обучения занятые в трудовой деятельности, в большей степени подготовлены к требованиям трудового рынка после окончания вуза. Выпускник в ситуации высокого уровня безработицы и отсутствия профессионального опыта на рынке труда будет чувствовать себя весьма неуверенно. В этой ситуации выпускник может попытаться прибегнуть к миграции как к средству решения проблем с работой и достойным уровнем ее оплаты. В свою очередь наличие как работы, так и профессионального опыта делает его положение на рынке труда более комфортным. 
Вначале рассмотрим распределение миграционных ориентаций всего массива респондентов в зависимости от наличия или отсутствия работы в процессе обучения в вузе.

Таблица 10. Миграционные ориентации у респондентов в зависимости от наличия или отсутствия работы

\begin{tabular}{l|c|c|c|c|c}
\hline Работаете ли вы в настоящее время & ИМО & $\begin{array}{c}\text { Не } \\
\text { ориентированы } \\
\text { на миграцию, } \\
\%\end{array}$ & $\begin{array}{c}\text { Ориентированы } \\
\text { на миграцию, } \\
\%\end{array}$ & $\begin{array}{c}\text { Трудно } \\
\text { сказать, \% }\end{array}$ & Всего \\
\hline 1. Да, есть постоянная работа & $-0,16$ & 51,0 & 35,2 & 13,8 & 100 \\
2. Да, есть временная работа & $-0,09$ & 44,7 & 35,2 & 20,2 & 100 \\
3. Иногда подрабатываю (от случая & $-0,06$ & 44,7 & 34,7 & 24,1 & 100 \\
к случаю) & $-0,05$ & 42,8 & 38,0 & 19,2 & 100 \\
4. В настоящее время не работаю & $-0,04$ & 41,3 & 37,7 & 21,0 & 100 \\
5. Не работаю & $-0,07$ & 43,5 & 36,7 & 19,8 & 100 \\
\hline
\end{tabular}

Данные опроса показывают неоднозначное влияние наличия или отсутствия работы на миграционные ориентации работающих студентов (таблица 10). С учетом того, что на процесс формирования миграционных ориентаций влияет множество факторов, полученные данные неоднозначны. С одной стороны, миграционные ориентации фиксируются как у работающих, так и у неработающих выпускников, а с другой, - во всех группах преобладают респонденты, не ориентированные на миграцию.

Из таблицы 10 видно, что имеющие постоянную работу студенты, хотя и намерены мигрировать, как и неработающие, но в меньшей степени $(И М О=-0,16)$, чем те, кто: а) работают только временно $(-0,09)$; в) иногда подрабатывают (от случая к случаю: $-0,06) ;$ с) во время опроса не работали $(-0,05)$ или не работали вовсе $(-0,04)$.

Таблица 11. Влияние уровня заработка студентов на миграционные ориентации, \%

\begin{tabular}{|c|c|c|c|c|c|c|c|c|}
\hline \multirow{2}{*}{$\begin{array}{l}\text { Каким был } \\
\text { размер Вашего } \\
\text { заработка за } \\
\text { прошедший } \\
\text { месяц, не } \\
\text { включая } \\
\text { стипендию (в } \\
\text { национальной } \\
\text { валюте)? }\end{array}$} & \multirow[b]{2}{*}{ ИМО } & \multicolumn{6}{|c|}{$\begin{array}{c}\text { Как Вы сами относитесь к вероятности Вашего отъезда за пределы } \\
\text { страны, гражданином которой Вы являетесь? }\end{array}$} & \multirow[b]{2}{*}{$\begin{array}{l}\text { Итог } \\
\text { о }\end{array}$} \\
\hline & & 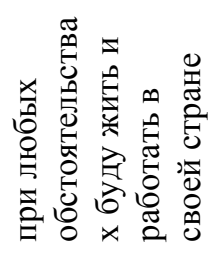 & 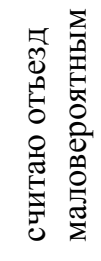 & 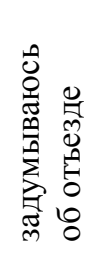 & 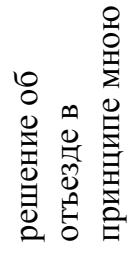 & 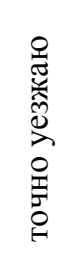 & 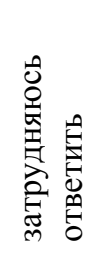 & \\
\hline От 200 до 1000 & 0,48 & 6,8 & 13,6 & 52,3 & 6,8 & 9,1 & 11,4 & 100,0 \\
\hline От 1001 до 2000 & 0,28 & 12,3 & 15,4 & 33,8 & 13,8 & 7,7 & 16,9 & 100,0 \\
\hline От 2001 до 3000 & 0,09 & 7,2 & 33,3 & 37,7 & 10,1 & 1,4 & 10,1 & 100,0 \\
\hline От 3001 до 4000 & $-0,18$ & 25,0 & 25,0 & 14,3 & 14,3 & 3,6 & 17,9 & 100,0 \\
\hline От 4001 до 5000 & 0,09 & 14,3 & 23,8 & 28,6 & 9,5 & 9,5 & 14,3 & 100,0 \\
\hline От 5001 и выше & 0,09 & 16,1 & 29,0 & 29,0 & 16,1 & 6,5 & 3,2 & 100,0 \\
\hline Итого, \% & 0,17 & 11,9 & 23,8 & 35,7 & 11,5 & 6,0 & 12,7 & 100,0 \\
\hline Человек & & 31 & 60 & 90 & 30 & 15 & 32 & 258 \\
\hline
\end{tabular}

Все же наличие работы незначительно влияет на желание остаться в стране. Как показывает опрос, у большинства респондентов к выпускному курсу сложилось достаточно реальное представление о размере будущего дохода от работы по полученной профессии. По оценкам студентов, заработок и в городе, где находится вуз, и в прежнем месте жительства в большинстве своем не может удовлетворить сформировавшуюся у выпускников вузов установку на высокое престижное потребление. Данным фактором, 
скорее всего, и можно объяснить достаточно высокий уровень ориентации на миграцию работающих респондентов. В этой связи логично рассмотреть, как влияет размер заработка на миграционные ориентации.

Предположение о влиянии размера заработка на уровень миграционных ориентаций студентов выпускных курсов иллюстрирует таблица 11.

Действительно, уровень миграционных ориентаций наиболее высок в группе работающих респондентов с самым низким доходом за последний месяц: ИМО работающих студентов с заработной платой от 200 до 1000 леев имеет самое высокое значение во всей группе респондентов $(0,48)$. Иначе говоря, $68,2 \%$ респондентов, хотя и с разной степенью уверенности, но планируют уехать из страны. Планирует остаться в Молдавии из группы с самыми низкими доходами только каждый пятый респондент. При любых обстоятельствах будут жить и работать в своей стране 6,8\% и 13,6\% считают свой отъезд маловероятным. С ростом доходов доля миграционных ориентаций выпускников сокращается: чем выше получаемый доход, тем ниже ИМО. В группе с доходом от 3000 до 4000 леев ИМО имеет отрицательное значение $(-0,18)$. В целом же группы с доходом от 4000 леев и выше демонстрируют небольшое преобладание миграционных ориентаций при наличии достаточно высокой доли тех респондентов, которые высказывают готовность остаться в стране $($ ИМО = 0,09). Так, в группе с доходом более 5000 леев в месяц 16,1\% респондентов готовы остаться в стране при определенных обстоятельствах, а 29,0\% считают вероятность своего отъезда из страны незначительной.

Можно предположить, что заработная плата в 5000 леев и более (417\$) представляет в стоимостном выражении плату за немиграцию. Однако общество не в состоянии удовлетворить финансовые ожидания выпускников: в 2013 г. средняя заработная плата составляла 4241,2 лея $(352,4 \$)$.

\section{ВНУТРЕННЯЯ МИГРАЦИЯ КАК СРЕДСТВО ПОДТВЕРЖДЕНИЯ ИЛИ ПОВЫШЕНИЯ «РОДИТЕЛЬСКОГО» ОБРАЗОВАТЕЛЬНОГО СТАТУСА СТУДЕНТАМИ ВЫПУСКНЫХ КУРСОВ МОЛДАВСКИХ ВУЗОВ}

Проблема в том, насколько нынешними выпускниками вузов: а) статус родителей будет воспроизведен; б) будет достигнут более «высокий», чем родительский образовательный статус. Миграция в вуз создает необходимую социальную базу и для первого, и для второго. По крайней мере, можно констатировать, что без миграции в вуз такая возможность была бы минимальной.

С этой целью мы сравним высшее образование родителей и их детей, получающих высшее образование, мигрируя в Кишинев.

Из 100\% выпускников молдавских вузов:

- проживавших в малых городах страны, 50,6\% с помощью миграционных перемещений в вузовские центры в столице и большом городе повышают «родительское» образование до высшего, 40,1\% подтверждают «родительское» 
образование, у 6,8\% респондентов данные о «родительском» образовании отсутствуют (у них нет родителей), 2,5\% на вопрос не ответили;

- проживавших в сельских населенных пунктах страны, 54,9\% с помощью миграционных перемещений в вузовские центры в столице и большом городе повышают «родительское» образование до высшего, 36,4\% подтверждают «родительское» образование, у 6,1\% респондентов данные о «родительском» образовании отсутствуют (у них нет родителей), 2,6\% на вопрос не ответили.

\section{ЗАКЛЮЧИТЕЛЬНЫЙ ЭТАП МИГРАЦИОННЫХ ОРИЕНТАЦИЙ СТУДЕНТОВ ВЫПУСКНЫХ КУРСОВ}

Третий, заключительный этап миграционных ориентаций студентов выпускных курсов представлен в виде жизненных планов после окончания вуза. Желаемое миграционное поведение в данном случае представляет собой результат трехлетней жизни в новом интеллектуальном и пространственном (для приезжих студентов) окружении университетского образования, возможность реализовать свои жизненные ориентации в новых культурных, социальных или экономических условиях.

Таблица 12. Миграционные ориентации выпускников старших курсов в зависимости от места проживания непосредственно перед поступлением (или переводом) в вуз, в котором учатся сейчас, \%

\begin{tabular}{|c|c|c|c|c|c|c|}
\hline \multirow[b]{2}{*}{$\begin{array}{c}\text { Где вы проживали } \\
\text { непосредственно перед } \\
\text { поступлением (или переводом) } \\
\text { в вуз, в котором учитесь } \\
\text { сейчас? }\end{array}$} & \multicolumn{5}{|c|}{ Где Вы собираетесь жить после окончания вуза? } & \multirow[b]{2}{*}{ Всего } \\
\hline & 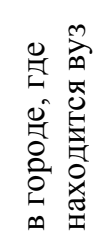 & 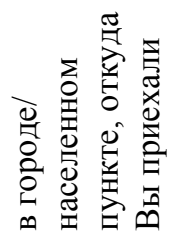 & 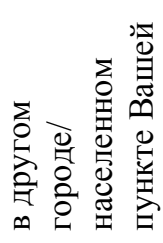 & 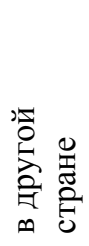 & 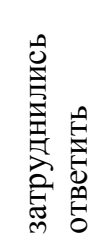 & \\
\hline $\begin{array}{l}\text { В том же городе/населенном } \\
\text { пункте, где находится вуз }\end{array}$ & 53,5 & 0,0 & 2,1 & 24,7 & 19,7 & 100,0 \\
\hline $\begin{array}{l}\text { В другом городе/населенном } \\
\text { пункте }\end{array}$ & 36,6 & 17,7 & 4,4 & 21,3 & 20,0 & 100,0 \\
\hline Итого & 43,5 & 10,5 & 3,5 & 22,7 & 19,8 & 100,0 \\
\hline Российская Федерация & 51,6 & 7,1 & 15,2 & 6,9 & 19,3 & 100,0 \\
\hline
\end{tabular}

В целом по массиву (таблица 12) миграционные ориентации студентов выпускных курсов молдавских вузов распределяются следующим образом: «немигранты» $(43,5 \%)$ - те, кто собирается остаться в городе, где проходили обучение; «возвратные мигранты» $(10,5 \%)$ - выпускники, собираются вернуться в населенный пункт, откуда приехали на учебу; «внутренние мигранты» $(3,5 \%)$ - планируют переехать в другой город/село в пределах Молдавии; «международные мигранты» (22,7\%) - планируют переехать в другую страну.

В то же время жизненный этап до поступления в вуз оказал различное влияние на формирование миграционных ориентаций или на их отсутствие. Выпускники, непосредственно проживавшие перед поступлением (или переводом) в населенном пункте, в котором находится вуз, значительно больше ориентированы немиграционно, чем выпускники, проживавшие до поступления в другом городе/населенном пункте 
(соответственно 53,5 и 36,6\%). Напомним, что подавляющее число респондентов до поступления проживало в Кишиневе, городе с наибольшими социально-культурными и экономическими возможностями. Именно данный фактор и приводит к тому, что немигранты остаются в подавляющем большинстве в своем городе, в столице страны Кишиневе. В то же время именно эта группа в большей степени ориентирована на внешнюю миграцию: собираются жить в другой стране 24,7\%, в другом населенном пункте Молдавии 2,1\%. Как правило, выпускники, проживающие в столичном городе, обладают большими и социальными, и экономическими возможностям для отъезда за пределы страны, а переезд из столицы в другой населенный пункт Молдавии рассматривается ими как жизненная неудача.

Миграционные ориентации выпускников, приезжающих из других населенных пунктов, показывают больший разброс: 17,7\% планируют возвращение в населенный пункт, откуда приехали; 4,4\% ориентируются на внутреннюю миграцию и 21,3\% - на внешнюю миграцию. Важно отметить, что каждый третий из приехавших на учебу (36,6\%) планирует остаться в городе, где находится вуз (в основном в Кишиневе).

По той же причине внутренних мигрантов в первой группе вдвое меньше, чем во второй (соответственно 2,1 и 4,4\%). Уровень жизни в столице и Бельцах выше, чем в других населенных пунктах, и выпускники - жители этих городов не стремятся переехать в другие регионы страны. «Международных мигрантов» в первой группе на 3,4\% больше, чем во второй. Скорее всего, речь идет о большем экономическом, социальном и культурном капитале студентов, проживающих в населенных пунктах, где расположены вузы.

Как результат, существующие тенденции в миграционных ориентациях обеих групп приведут к тому, что пострадают, прежде всего, малые города и села Молдавии: из них в первую очередь вымывается молодой интеллектуальный потенциал как в столицу, так и за пределы страны. Тенденция, впрочем, характерная не только для Молдавии.

Представляет интерес сравнение миграционных ориентаций студентов выпускных курсов Молдавии и России. Несмотря на всю условность подобного сравнения с социальнокультурной точки зрения, есть и вполне приемлемые методологические условия для сравнения: исследование в Молдавии проводилось по анкете, разработанной авторами аналогичного российского исследования. Авторами молдавского исследования были проведены незначительные модификации в опросном листе с учетом особенностей вузовского обучения в Молдавии. Отличия в основном относятся к объекту исследования: $89,7 \%$ респондентов в молдавском исследовании обучаются в столице Республики и только $10,3 \%$ - в региональных вузах. В российском исследовании все $100 \%$ респондентов студенты выпускных курсов региональных вузов.

При сравнении типов миграционных ориентаций в обоих исследованиях мы наблюдаем существенные различия. Российские студенты региональных вузов в большей степени, чем выпускники молдавских вузов, демонстрируют «немиграционные» ориентации. «Немигрантов» среди студентов выпускных курсов вузов в российском исследовании на 8,1\% больше, чем среди молдавских студентов (51,6 и 43,5\% соответственно); «внутренних мигрантов» почти в пять раз больше (в российском исследовании - 15,2\%, в молдавском - 3,5\%). Вывод, который можно сделать на основании 
полученных данных: молдавских студентов жизнь в столице привлекает в значительно меньшей степени, чем российских жизнь в городах, даже не имеющих столичного статуса.

Наибольшие различия между российскими и молдавскими студентами выпускных курсов наблюдаются в категории «международных мигрантов». Среди молдавских выпускников «международных мигрантов» почти втрое больше, чем среди российских: $22,7 \%$ в Молдавии и 6,9\% в России. Очевидно, выталкивающие факторы действуют на выпускников молдавских вузов в значительно большей степени, чем на российских выпускников. Россия является лидером среди наиболее привлекательных стран внешней миграции для выпускников молдавских вузов (29,5\%), на втором и третьем месте США $(13,7 \%)$ и Германия $(19,7 \%)$.

\section{Выводы}

Объем совокупного миграционного потенциала выпускников столичных и региональных вузов Молдавии довольно значителен и составляет $36,7 \%$ респондентов. Основное направление миграционных ориентаций студентов выпускных курсов молдавских вузов «миграция в другую страну» (22,8\%), доля возвратных мигрантов составляет 10,5\% и внутренних мигрантов - 3,5\%.

Иногородние студенты демонстрируют большую активность в области внутренней миграции: 4,4\% против 2,1\% среди местных выпускников. В то же время местные выпускники в большей степени ориентированы на внешнюю миграцию (соответственно $24,7$ и $21,3 \%)$.

Неудовлетворенность качеством обучения способствует формированию миграционных ориентаций в процессе обучения в вузе: 22,9\% неудовлетворенных качеством обучения студентов выбрали бы другой вуз, другой факультет (направление подготовки) в другой стране.

Выпускники высшего учебного заведения ориентируются в последующем миграционном передвижении на достижения как социального (ролевого), так и экономического (инвестиционного) плана. Ожидаемая заработная плата выпускника, если он вернется в свой родной город, составляет «от 2521,1 до 5081,5 леев». Прогноз доходов «будущей семьи» выпускника в Молдавии лежит между доходами «бедной» семьи и семьи «со средним достатком».

Чтобы нормально жить в городе обучения, необходимо зарабатывать, в среднем, (по оценкам студентов) 9275,9 леев в месяц. Сумма существенно меньшая, чем та, на которую они могут рассчитывать: от 2866,1 до 4778,0 леев в месяц.

В предполагаемой стране эмиграции ожидаемый заработок, в среднем, может составлять (по оценкам студентов) 20077,4 леев или 1673,1\$ в месяц. 


\section{ЛИТЕРАТУРА}

Барбер Б. (1972). Структура социальной стратификации и тенденции социальной мобильности // Американская социология: перспективы, проблемы, методы. М.: Прогресс: 235-247.

Варшавская Е.Я., О.С. Чудиновских (2014). Миграционные планы выпускников региональных вузов России // Вестник Московского университета. Сер. Экономика. №3. URL: http://publications.hse.ru/articles/129904514 (дата обращения: 19.09.2015).

Малахова А. (2007). Престиж в цене // Expert Online. 12 октября. URL: http://expert.ru/2007/10/12/prestizh1/ (дата обращения: 22.06.2015).

Молодикова И. (ред.) (2006). Миграция в зеркале стран СНГ (молодежный ракурс), URL: http://www.kniga.seluk.ru/k-ekonomika/755512-1-migraciya-zerkale-stran-sngmolodezhniy-rakurs-pod-redakciey-irini-molodikovoy-moskva-2006-proekt-iniciirovan.php] (дата обращения: 16.09.2015).

Татарова Г.Г. (1999). Методология анализа данных в социологии (введение) / Учебник для вузов. М.: Nota bene. URL: http://socioline.ru/pages/gg-tatarova-metodologiya-analizadannyh-v-sotsiologii) (дата обращения: 22.08.2015).

Чередниченко Г.А. (2013). Образование и профессиональные траектории молодежи: исследовательские концепты. URL: http://www.isras.ru/Sociologicalmagazine.03.2013.html?\&printmode (дата обращения: 09.09.2015).

Dustmann C., A. Glitz (2011). Migration and Education. URL: http://econpapers.repec.org/paper/norwpaper/2011011.htm (дата обращения: 07.01.2015).

Educatia in Republica Moldova (2013). Publicatie statistica 2012/2013. URL: http://www.statistica.md/public/files/publicatii_electronice/Educatia/Educatia_RM_2013.pdf (дата обращения: 17.09.2015).

Harper S. (2013). Future Identities: Changing identities in the UK - the next 10 years DR13: What will the age profile of the population mean for notions of identity in the next 10 years? URL: https://www.gov.uk/government/uploads/system/uploads/attachment_data/file/275773/13515-age-profile-of-population-for-identity.pdf (дата обращения: 12.01.2015).

Houle J.N. (2014). A generation indebted: young adult debt across three cohorts. URL: http://jnhoule.squarespace.com/storage/Houle2014_GenIndebted.pdf (дата обращения: 9.01.2015). 


\title{
MIGRATION PLANS OF GRADUATES OF MOLDOVIAN UNIVERSITIES *
}

\section{VALERIU MOSNEAGA, VALENTIN TURCAN}

VALERIU G. Mosneaga. Moldova State University

Valentin D. TurCan. Moldova State University. E-mail: vals6412@yandex.ru.

DATE RECEIVED January 2015.

\begin{abstract}
The migration plans of Moldovan university graduates are oriented above all towards departing to other countries, returning to their previous place of residence, and migrating to "another locality" within the country. Potential migration of graduates is motivated by factors such as "decent living standards", "the possibility of attaining high income", and "the cultural environment". Returning migrants are counting most of all on a good salary and the possibility of finding an interesting job, as well as on the help of relatives.

The factors prompting them to migrate are first and foremost economic: the expected income of the majority of graduates does not allow them to achieve the status of a "middle-income family". The results of this research can be used in decision-making in the domains of youth, migration, and education policies.

Information on potential migration from among the student youth is important, as, first of all, it allows an assessment of the effectiveness of college education in providing the Republic of Moldova with highly qualified employees. Secondly, it allows one to determine the professions most vulnerable to the "braindrain" phenomenon. And thirdly, such information is vital for the safety of those graduates who are about to realize their migration plans, both within the country and outside of it.
\end{abstract}

Key words: educational migration; internal migration; return migration; international migration; migration intention.

* THE STUDY WAS CONDUCTED BY THE GROUP OF SOCIOLOGISTS FROM MOLDOVA STATE UNIVERSITY WITHIN THE PROJECT «EVALUATION OF MIGRATION CAPACITY OF MOLDOVAN UNIVERSITY GRADUATES», SUPPORTED BY THE FUNDAMENTAL RESEARCH PROGRAM OF THE HIGHER SCHOOL OF ECONOMICS (MOSCOW, RUSSIA) IN 2013.

\section{REFERENCES}

Barber B. (1972). Struktura socialnoy stratifikatsii I tendentsii socialnoy mobilnosti //

Amerikanskaya sociologia: perspective, problem metodi. Moskva: Progress: 235-247.

[Barber B. (1972). The structure of social stratification and trends of social mobility // American Sociology: Prospects, Problems and Methods. Moscow: Progress: 235-247].

Cerednicenko G.A. (2013). Obrazovanie I professionalnie traektorii molodeji: issledovatelskie contsepti. URL: http://www.isras.ru/Sociologicalmagazine.03.2013.html?\&printmode (data obrascenia: 09.09.2015). [Cerednicenko G.A. (2013). Education and professional trajectory of youth: research concepts. URL:

http://www.isras.ru/Sociologicalmagazine.03.2013.html?\&printmode (accessed: 09.09.2015)].

Dustmann C., A. Glitz (2011). Migration and Education. URL: http://econpapers.repec.org/paper/norwpaper/2011011.htm (accessed: 07.01.2015).

Educatia in Republica Moldova (2013). Publicatie statistica 2012/2013. URL: http://www.statistica.md/public/files/publicatii_electronice/Educatia/Educatia_RM_2013.pdf (access: 17.09.2015).

Harper S. (2013). Future Identities: Changing identities in the UK - the next 10 years DR13: What will the age profile of the population mean for notions of identity in the next 10 years? URL: 
https://www.gov.uk/government/uploads/system/uploads/attachment_data/file/275773/13515-age-profile-of-population-for-identity.pdf (accessed: 12.01.2015).

Houle J.N. (2014). A generation indebted: young adult debt across three cohorts. URL: http://jnhoule.squarespace.com/storage/Houle2014_GenIndebted.pdf (accessed: 09.01.2015).

Malakhova A. (2007). Prestij v tene // Expert Online. 12 Oktjabrja. URL: http://expert.ru/2007/10/12/prestizh1/ (data obrascenia: 22.06.2015). [Malakhova A. (2007). Prestige in the price // Expert Online. 12 Oktjabrja. URL: http://expert.ru/2007/10/12/prestizh1/ (accessed: 22.06.2015)].

Molodikova I. (red.) (2006). Migratsia v zerkale stran SNG (molodejniy rakurs). URL: http://www.kniga.seluk.ru/k-ekonomika/755512-1-migraciya-zerkale-stran-sngmolodezhniy-rakurs-pod-redakciey-irini-molodikovoy-moskva-2006-proekt-iniciirovan.php] (data obrascenia: 16.09.2015). [Molodikova I. (Ed.) (2006). Migration in the mirror of the CIS countries (youth perspective). URL: http://www.kniga.seluk.ru/k-ekonomika/755512-1migraciya-zerkale-stran-sng-molodezhniy-rakurs-pod-redakciey-irini-molodikovoy-moskva2006-proekt-iniciirovan.php (accessed: 16.09.2015)].

Tatarova G.G. (1999). Metodologia analiza dannih v sociologii (vvedenie) / Ucebnik dlea vuzov. Moskva: Nota bene. URL: http://socioline.ru/pages/gg-tatarova-metodologiya-analizadannyh-v-sotsiologii (data obrascenia: 22.08.2015). [Tatarova G.G. (1999). Methodology of data analysis in sociology (introduction) / textbook for high schools. Moscow: Nota bene. URL: http://socioline.ru/pages/gg-tatarova-metodologiya-analiza-dannyh-v-sotsiologii (accessed: 22.08.2015)].

Varshavskaya E.Ia., O.S. Chudinovskikh (2014). Migrationnie plani vipusknikov regionalnih vuzov Rossii // Vestnik Moskovskogo universiteta. Seria Ekonomika. №3. URL: http://publications.hse.ru/articles/129904514 (data obrascenia: 19.09.2015). [Warshawskaya E.Y., O.S. Chudinovskikh (2014). Migration plans of the Graduates of regional universities in Russia // Bulletin of Moscow University. Economy Series. №3. URL: http://publications.hse.ru/articles/129904514 (accessed: 19.09.2015)]. 